geophysics and astrophysics, and particularly from the physics of the ionosphere. J. G. Davies describes the application of radio techniques to the investigation of meteors, and presents some geophysical observations on meteor trails.

It is anticipated that the International Geophysical Year programme will add a great deal to our knowledge of the variations of intensity of cosmic rays. These variations are discussed by $D$. C. Rose in relation to geophysical and solar phenomena. In the review of radio-wave propagation by $R$. L. SmithRose greatest emphasis is given to ground-wave characteristics at low frequencies with their bearing on navigational aids, and to studies of propagation at high frequencies as influenced by the ionosphere.

Oceanographers are making more and more use of electronic equipment, both in experimental investigations and for the solution of theoretical problems. Although nearly all types of oceanographic observation can in fact be made without electronic instrumentation, greater precision and continuity can be achieved with its aid ; and a chapter is contributed by J. B. Hersey in which the nature and extent of electronic applications to this subject are described.

The final chapter, by B. S. Melton, deals with contributions of electronics to seismology and geomagnetism. It includes such topics as the use of feedback systems in seismological instruments, the nuclear precession magnetometer and magnetic recording.

This volume is a worthy successor to those which have appeared before. The material is extremely well presented and illustrated, and research workers wishing to pursue any of the subjects in greater detail will find the comprehensive bibliographies provided by all the authors a valuable feature.

J. A. Saxton

\section{PEST CONTROL}

\section{Advances in Pest Control Research}

Vol. 1. Edited by R. L. Metcalf. Pp. vii +514 . (New York : Interscience Publishers, Inc.; London : Interscience Publishers, Ltd., 1957.) 11 dollars.

$\mathrm{N}$ the preface to this book, pests are defined as organisms that compete with man for his food supply, damage his possessions and attack his person. Such an all-inclusive definition includes diseaseproducing organisms not usually classified as pests. Such breadth of definition is not unwelcome, as it may provide an opportunity for the ready transfer of ideas between what are closely related fields of work involving biologically active chemicals-the control of pests and disease-producing organisms. The use of poisons is not new, but it has assumed increasing importance in the past few decades. It is therefore not surprising that the greater part of this volume, the first in a series on pest control research, is devoted mainly to the problems involved in the discovery or use of chemicals for pest control. Indeed, it is a direct result of the fulfilment of one of the aims of this series to select subject-matter from recent research trends related to all phases of pest control, with emphasis on fundemental aspects. The other praiseworthy aims expressed are that the contributions shall be not only comprehensive reviews but also critical evaluations of new concepts and develop. ments. It is also intended to encourage the presentation of personal viewpoints so that "Advances in Pest
Control Research" shall be a stimulating book as well as a reference work.

The diversity of the subjects, their status and nature has inevitably affected the level of treatment in each article. It is interesting and useful to be able to compare the different outlooks on what are fundamentally the same basic problems in different spheres of pest control. This can be done in the current volume by comparing the three articles on the chemistry and mode of action of pesticides, which deal in turn with herbicides, fungicides and organo-phosphorus insecticides. In contrast the article on repellants for biting arthropods deals with a less investigated subject. The importance of the selective use and action of pesticides is brought out in the article on health hazards of pesticides, while the difficulties are illuminated by two articles which deal with the estimation of pesticide residues, one by chemical and the other by biological methods. Selective action in a more restricted sense is dealt with by the article on the status of systemic insecticides, which is largely concerned with the more practical aspects of the subject. It also touches on combined biological and chemical control. The effects of control measures on population balance are also included in the article on recent advances on the control of soil fungi.

The first volume promises well for the utility of the series, both as a source of stimulating ideas and a reference work. It will be necessary, however, to suppress the tendency to produce an undigested catalogue such as is offered in the article on the uses of radioisotopes.

K. A. LORD

\section{CEREALS AND CLIMATE}

\section{Wheat-Climate Relationships \\ Barley-Climate Relationships \\ Rye-Climate Relationships}

And the Use of Phenology in Ascertaining the Thermal Requirements of Wheat, Barley and Rye. By M. Y. Nuttonson. (Based on Data of North America and of Some Thermally Analogous Areas of North America, in the Soviet Union, Finland, Poland, and Czechoslovakia.) Pp. vii $+388, \mathrm{pp}$. vi +280 , pp. $v+219$, respectively. (Washington, D.C. : American Institute of Crop Ecology, 1955, 1957 and 1958.) n.p.

THESE volumes issued by the American Institute of Crop Ecology are concerned with an analysis of the effect of climate on growth of wheat, barley and rye based on a large volume of data on the phenology of these three cereals in North America, Finland, Poland, the U.S.S.R. and Czechoslovakia, assembled from records and reports of agricultural experimental stations. This information has been summarized in a large number of tables and figures. All the phenological data for winter wheat in the United States concern Kharkov, strain C.I. 1442, which has become the standard against which the performance of other varieties is measured in many agricultural experiment stations. The variety Thatcher is used as a standard for spring wheat. The records for Finland refer mainly to variety Varma (winter wheat) and Timantti (spring wheat). In considering the U.S.S.R., however, phenological records of a great number of varieties had to be used because of the diverse varieties cultivated in different areas. 